\title{
Instrumentos de política pública para la conservación: su nacimiento y evolución en Colombia*
}

\author{
Karla Juliana Rodríguez R. y V. Sophie Ávila Foucat**
}

\begin{abstract}
Resumen
Se analiza el surgimiento y evolución de los únicos IEV que en el país se han diseñado para la conservación de los recursos naturales: la certificación forestal (CF) y el pago por servicios ambientales (PSA). Las entrevistas realizadas a actores clave muestran que en Colombia la fuerza de las tendencias internacionales promovió el surgimiento de dichos instrumentos. Sin embargo, aunque existen avances normativos y algunas experiencias en la implementación, la debilidad institucional genera que ninguno de los instrumentos logre avances suficientes para consolidarse como política pública nacional.
\end{abstract}

\begin{abstract}
In this paper we analyze the emergence and evolution of two voluntary economic instruments for the conservation of natural resources in Colombia: forest certification (CF) and payment for environmental services (PES). Interviews with key actors show that international trends promoted the emergence of such instruments. However, although there is some normative progress and there are some experiences in implementation, institutional weakness generates none of the instruments to achieve sufficient progress to consolidate itself as a national public policy.
\end{abstract}

Palabras clave: instrumentos económicos voluntarios, conservación, certificación, pago por servicios ambientales y reducción de emisiones por deforestación y degradación (REDD).

Key words: voluntary economic instruments, conservation, certification, payments for environmental services, Reducing Emissions from Deforestation and Forest Degradation (REDD).

* Las autoras agradecen al Consejo Nacional de Ciencia y Tecnología CONACYT por el apoyo financiero para adelantar el presente trabajo, al Maestro Raúl Antonio Riveros y los Doctores Américo Saldívar de la Facultad de Economía de la UNAM y Alonso Aguilar Ibarra del Instituto de Investigaciones Económicas de la UNAM por las observaciones realizadas y a los profesionales y expertos del Ministerio de Ambiente y Desarrollo Sostenible, Ministerio de Agricultura y Desarrollo Rural, Artesanías de Colombia, Instituto Colombiano de Normas Técnicas y Certificación, Patrimonio Natural Fondo para la Biodiversidad y Áreas Protegidas, Corporación Ecoversa, Centro para la Investigación en Sistemas Sostenibles de Producción Agropecuaria, Conservation Strategy Fund, Grupo de Trabajo en Certificación Forestal Voluntaria, Mesa REDD y Universidad de los Andes, que amablemente aceptaron ser entrevistados.

** Karla Juliana Rodríguez R., es Maestra en Economía del Medio Ambiente y Recursos Naturales y estudiante del Doctorado en Economía de los Recursos Naturales y Desarrollo Sustentable del Instituto de Investigaciones Económicas de la UNAM.

V. Sophie Ávila Foucat tiene un Ph.D. en Economía Ambiental y Manejo de Ecosistemas y esInvestigadora Titular B del Instituto de Investigaciones Económicas de la UNAM. 


\section{Introducción}

as políticas públicas ambientales orientadas al uso y conservación de los recursos naturales toman mayor relevancia en países megadiversos. Países como Colombia son un caso excepcional de diversidad étnica, cultural y ecosistémica. De los ciento catorce millones de hectáreas de superficie terrestre (114'174.800 ha), el 51\% se encuentra con cobertura vegetal boscosa (Cabrera et al., 2011). Cobertura que en aproximadamente un 50\% está siendo habitada y aprovechada por comunidades indígenas (43\%) y afrodescendientes (5\%) (IDEAM, 2010). A pesar de la importancia de la diversidad biológica en Colombia, el país ha vivido un proceso acelerado de transformación de hábitats y ecosistemas naturales (Cabrera et al., 2011), resaltando así la importancia de avanzar en el país con políticas públicas para conservar los recursos naturales de la nación, contemplando tanto la preservación, como el mantenimiento, uso sostenible, restauración y mejora del ambiente natural (IUCN, 1980).

Los instrumentos diseñados e implementados para la protección del ambiente se clasifican de diferentes formas. Si bien las clasificaciones más básicas dividen a los instrumentos en dos grupos, enfoque directo (instrumentos de comando y control) y enfoque indirecto (instrumentos económicos o de mercado) (Pérez et al, 2010; Dietz y Vollebergh, 2002; CEPAL et al., 1998, Howlett, 2007), existen clasificaciones que han considerado diversas y novedosas categorías denominadas de la siguiente forma: regulación desafiante y acuerdos voluntarios (Russel y Powell, 2002; Barde, 1995), instituciones cooperativas (Hanley et al., 2007), políticas de información que involucran al público (Sterner, 2008; Banco Mundial, 1997), contratos (Horan y Shortle, 2001), instrumentos no obligatorios (Khanna, 2001), o instrumentos voluntarios (Parkhurst et al., 2002).

Adicionalmente, los instrumentos de política ambiental han tenido en su mayoría una fuerte tendencia a la internalización de externalidades negativas asociadas al daño ambiental y pérdida de bienes y servicios ambientales. Sin embargo, para abordar la conservación de los recursos naturales se han diseñado instrumentos económicos que de acuerdo con Baumol y Oates (1988) y Wunder (2005) están orientados a incentivar la conservación y a internalizar sus costos. Dentro de éstos, existe una reducida gama de instrumentos que tienen generalmente un carácter voluntario en su implementación (acuerdos voluntarios, provisión de información) y que son el objeto de estudio del presente artículo. 
En concordancia, recientes investigaciones han identificado la necesidad de implementar nuevos y flexibles instrumentos con el objetivo de alcanzar la protección de los recursos naturales, el desarrollo local y minimizar los conflictos sociales (Jones et al., 2012; Chowdhury y Koike, 2010; Matose, 2006; Misra y Kant, 2004). En este sentido se han desarrollado los instrumentos económicos voluntarios, clasificación que aunque no ha sido ampliamente considerada, hace referencia a los instrumentos no coercitivos y cuya participación es decisión de cada individuo o comunidad, como es el caso de la certificación y el pago por servicios ambientales.

Aunado a lo anterior, se ha hecho énfasis en la literatura sobre las políticas de "segunda generación" en las cuales el contexto y la naturaleza de cada instrumento han sido tomados en cuenta para tratar de implementar varios instrumentos en un mismo territorio, idealmente para formar una estrategia de política pública integrada (Howlett, 2007; Rayner y Howlett, 2009). Es por ello que el presente artículo se interesa en estudiar dos tipos de instrumentos cuya implementación se da en un mismo territorio.

Estos dos tipos de instrumentos permiten reducir algunas fallas de mercado que impiden alcanzar la eficiencia en actividades como la conservación de los recursos naturales. La certificación es un instrumento económico que hace parte de la categoría de provisión de información, es una etiqueta por el cumplimiento voluntario de ciertas normas ambientales.

En Colombia, la política de conservación ha sido abordada desde la década de los noventa a través de la certificación forestal (CF), entendida como el proceso que permite identificar si un producto forestal maderable o no maderable, proviene de un bosque manejado con criterios de sostenibilidad (GTZ et al., 2004). Posteriormente, desde el 2005 el Ministerio de Ambiente creó el Sello Ambiental Colombiano (SAC), un nuevo instrumento de certificación que analiza todas las etapas del proceso productivo (extracción, transformación y comercialización) para la conformación de diferentes bienes entre ellos algunos provenientes de la biodiversidad.

Por otra parte, el pago por servicios ambientales (PSA), entendido como una transferencia de recursos entre actores sociales con el objetivo de crear incentivos que permitan alinear las decisiones individuales o colectivas sobre el uso de la tierra y los intereses sociales sobre el manejo de recursos naturales (Muradian et al., 2010), es un instrumento que bajo este nombre PSA desde inicios de este siglo ha estado en constante construcción en Colombia. En los últimos años el país ha avanzado en el diseño de un nuevo instrumento, la reducción de emisiones por deforestación y degradación (REDD), instrumento que de acuerdo con Coomes et al. (2008) y Laurance (2007) puede ser considerado un pago por servicios ambientales. 
Estos instrumentos son los instrumentos voluntarios que se han diseñado en Colombia con el objetivo de ofrecer soluciones a problemas prioritarios, que dada su urgencia deben ser abordados a través de las políticas públicas del país. Por ello, es pertinente analizar el surgimiento, la evolución, logros obtenidos y retos de éstos, de tal manera que en concordancia con Aguilar (2009) éste análisis sustente el diseño e implementación de instrumentos de política futuros, así como políticas más integrales acordes a realidades complejas (Howlett, 2009).

Por esta razón, el presente artículo tiene como objetivo analizar en conjunto el surgimiento, la evolución y las tendencias en la implementación de los instrumentos económicos voluntarios que en Colombia se han desarrollado para conservar sus recursos naturales.

A continuación se describe brevemente la metodología empleada, posteriormente los resultados se presentan para dos instrumentos de certificación (certificación forestal y sello ambiental colombiano) y para dos instrumentos de pago por servicios ambientales (PSA experiencia nacional y reducción de emisiones por deforestación y degradación) y finalmente se realiza la discusión de los resultados obtenidos.

\section{Metodología}

El análisis se centra en el surgimiento, evolución y tendencias de los instrumentos económicos voluntarios (IEV) para la conservación: Certificación (Certificación forestal - CF y Sello ambiental colombiano - SAC) y Pago por servicios ambientales (PSA experiencia nacional y Reducción de emisiones por deforestación y degradación - REDD) en Colombia.

En el surgimiento, se analizaron los factores a nivel nacional e internacional que influyeron en la creación de los instrumentos, en la evolución se formularon preguntas relacionadas con cambios conceptuales en el diseño, la normatividad y la institucionalidad para su conceptualización e implementación, así como el estado actual del instrumento. Finalmente, las tendencias hacen referencia a la visión a futuro y las acciones necesarias para alcanzarla.

El análisis de los puntos antes señalados se basa en entrevistas personales a profundidad realizadas entre los meses de junio y diciembre de 2011. Este tipo de entrevistas asegura elevadas tasas de respuesta, la posibilidad de precisar y aclarar las preguntas estimulando testimonios más completos y la oportunidad de percibir la reacción del entrevistado, apreciar actitudes y prejuicios (Garza 1970, Babbie 1988). Se realizaron 19 entrevistas semi- 
estructuradas a actores clave que han estudiado y abordado a profundidad la conservación de los recursos naturales en el país, contribuyendo al diseño y/o implementación de estos instrumentos económicos en distintas etapas y que actualmente hacen parte de los equipos de trabajo de instituciones del sector ambiental como: Ministerio de Ambiente y Desarrollo Sostenible (MADS), Ministerio de Agricultura y Desarrollo Rural (MADR), Artesanías de Colombia, Instituto Colombiano de Normas Técnicas y Certificación (ICONTEC), Patrimonio Natural Fondo para la Biodiversidad y Áreas Protegidas, Corporación Ecoversa, Centro para la Investigación en Sistemas Sostenibles de Producción Agropecuaria (CIPAV), Conservation Strategy Fund (CSF), Grupo de Trabajo en Certificación Forestal Voluntaria (GTCFV), Mesa REDD y Universidad de los Andes.

Teniendo en cuenta que los instrumentos de certificación han involucrado en su diseño e implementación un menor número de actores en comparación con los de pago por servicios ambientales, como se muestra en el cuadro 1 , se realizaron siete entrevistas a expertos en instrumentos de certificación y doce a expertos en pago por servicios ambientales.

\section{Cuadro 1. Entrevistas realizadas por instrumento y sector}

\begin{tabular}{|c|c|c|c|c|c|}
\hline \multirow{2}{*}{ Instrumento Económico Voluntario } & \multicolumn{4}{|c|}{ Sector } & \multirow{2}{*}{$\begin{array}{c}\text { № } \\
\text { Entrevistas }\end{array}$} \\
\hline & Público & Privado & Mixto & ONG & \\
\hline Certificación & 3 & 2 & 1 & 1 & 7 \\
\hline Pago por servicios ambientales & 5 & 0 & 2 & 5 & 12 \\
\hline Total & 8 & 2 & 3 & 6 & 19 \\
\hline
\end{tabular}

Las entrevistas se desarrollaron siguiendo una estructura con cuatro componentes: surgimiento, evolución, implementación y tendencias de los instrumentos, apartados que se desarrollaron en aproximadamente una hora. El análisis presenta retos interesantes debido a que ambos instrumentos han sido elaborados en temporalidades diferentes, se han involucrado distintas organizaciones y han tenido diferentes avances de implementación. Por ello, se enfatiza el sector al que pertenecen las instituciones de los entrevistados, siendo el sector público el más dominante debido a que son instrumentos de política pública. La selección de los actores clave como se mencionó anteriormente fue con respecto a su participación en el diseño o implementación y se buscó abarcar diversos sectores. La metodología no está basada en un análisis de impacto o de diseño de los instrumentos, sino en la descripción cronológica y contextual en la consolidación de éstos con 
la finalidad de tener conocimiento sobre el ciclo de éstas políticas públicas. Es el punto de partida para cualquier evaluación posterior.

\section{Resultados}

\section{Certificación}

La certificación ambiental en Colombia tiene sus inicios en la década de los noventa, con énfasis en productos como café, flores y banano (Ho, 1994). A finales de los noventa la certificación del manejo de bosques naturales como instrumento para la conservación de los recursos naturales es impulsada por organizaciones internacionales y más recientemente en el 2005, el Ministerio de Ambiente (hoy Ministerio de Ambiente y Desarrollo Sostenible, MADS) con la colaboración del Instituto Colombiano de Normas Técnicas y Certificación (ICONTEC) y Artesanías de Colombia, crea un instrumento de diferenciación ambiental (eco-etiqueta) el Sello Ambiental Colombiano (SAC).

\section{Certificación Forestal en Bosques Naturales (CF - BN)}

El surgimiento de la CF-BN, se relaciona con las tendencias internacionales, que a través del Consejo de Administración Forestal (FSC por sus siglas en inglés) la promovieron y motivaron que en 1995 surgiera en Colombia como iniciativa del conjunto de voluntades de la sociedad civil. Organizaciones como el Fondo mundial para la naturaleza (WWF por sus siglas en inglés), Fundación para la Educación y el Desarrollo Social (FES), Fundación Herencia Verde y procesos organizativos como Proceso de Comunidades Negras (PCN) y Organización Indígena de Antioquia (OIA), motivados por la necesidad de promover una estrategia integral para el manejo de los recursos naturales forestales, conformaron el Grupo de trabajo en certificación forestal voluntaria (GTCFV) con el objetivo de avanzar institucionalmente en el desarrollo del instrumento.

“Con la CFV se pretendía conciliar participativamente los intereses de los distintos grupos frente al recurso maderero, siguiendo tres pilares: todas las actividades alrededor del bosque deben ser ambientalmente sostenibles, socialmente benéficas y económicamente viables" (Entrevistado 16, 24 de octubre de 2011). 
La evolución de la certificación forestal, se resume en la figura 1, entre los eventos más importantes, se resaltan la conformación del Grupo de trabajo en certificación forestal voluntaria (GTCFV), su posterior consolidación como iniciativa nacional del Consejo de Administración Forestal (FSC por sus siglas en inglés) y el desarrollo de la norma para la CF de bosques naturales y guaduales (Guadua angustifolia).

Con relación a la implementación, se señala que no ha habido avances significativos en los bosques naturales del país, Colombia no cuenta con experiencias de comunidades con certificación en bosques naturales. Los logros se han centrado en sesenta hectáreas (60 ha) de guaduales certificadas y en que aproximadamente el $60 \%$ de las plantaciones comerciales cuentan con el certificado del estándar internacional FSC.

"A pesar del largo tiempo que lleva trabajándose el tema en el país, realmente la CFV no es ampliamente conocida. Sus resultados en bosques naturales no son alentadores" (Entrevistado 16, 24 de octubre de 2011).

Los reducidos avances en CF-BN se relacionan según los expertos con la falta de lineamientos de política clara en el sector forestal y por consiguiente con la ausencia de instrumentos que promuevan el manejo forestal sostenible.

\footnotetext{
"Hasta ahora se está reconociendo que al interior de los bosques siempre ha vivido y seguirá viviendo gente... Los apoyos que recibe la certificación son de ONG's principalmente internacionales, el Ministerio de Ambiente nunca ha apoyado con recursos financieros la implementación de la CF en el país" (Entrevistado 16, 24 de octubre de 2011).
}

En cuanto a las tendencias, los expertos señalan que a pesar de los escasos resultados en bosques naturales, el GTCFV junto con el FSC tienen entre sus metas continuar promoviendo la $\mathrm{CF}$ de bosques naturales, con la esperanza de que en próximos años se puedan realizar las primeras certificaciones por parte de comunidades indígenas y afrodescendientes; sin embargo, sus metas más claras se centran en incrementar para el 2012 en un $20 \%$ la superficie certificada con plantaciones comerciales. 


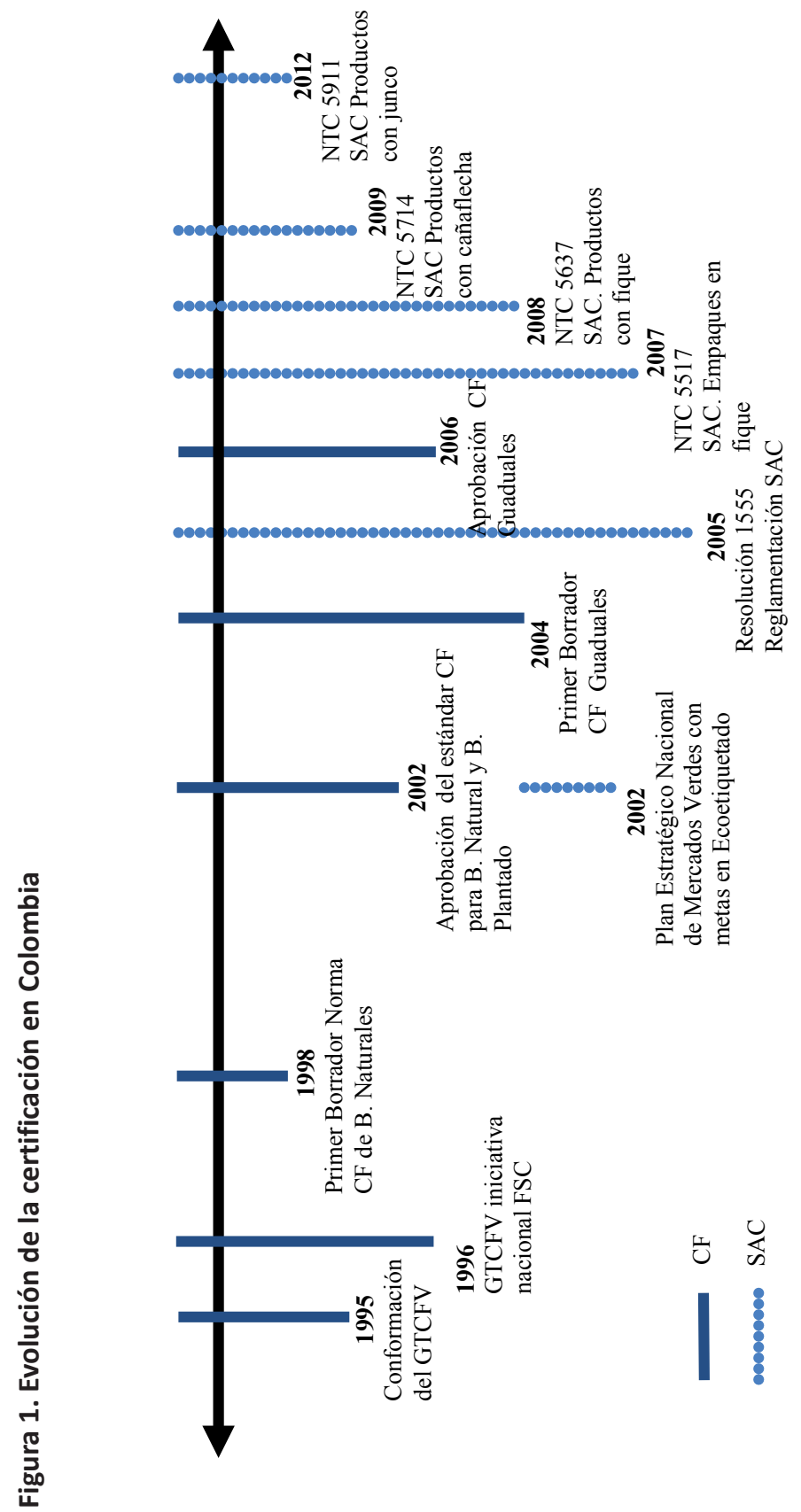


Esta etiqueta ecológica de carácter nacional (descrita en MAVDT ICONTEC, 2006), es una herramienta de diferenciación basada en ciclo de vida (considera las diferentes etapas del proceso productivo: extracción, transformación y comercialización), que se obtiene de forma voluntaria y es otorgada por una institución independiente (organismo de certificación nacional) por el cumplimiento de requisitos preestablecidos para su categoría.

El sello desarrolla tres categorías para tres especies vegetales que proveen fibras con las que se elaboraban artesanías y productos que en términos comerciales contaban con mayor madurez (fique - Fucraea sp., caña flecha - Gynerium sagittatum y junco - Typha sp.), dos de las cuales actualmente cuentan con denominación de origen.

De acuerdo con las entrevistas realizadas, el surgimiento del SAC se debe a sucesos principalmente de orden internacional, relacionados con el reconocimiento de las experiencias en esquemas de ecoetiquetado europeos y las señales internacionales sobre el cumplimiento de estándares ambientales en los procesos de producción lo cual permitía ampliar o incursionar en nuevos mercados y a su vez avanzar en una producción sostenible.

"La intención era estar acorde con las tendencias mundiales, el sello era una alternativa interesante de mercado" (Entrevistado 8, 7 de julio de 2011).

También se resalta entre los detonantes el reconocimiento de la necesidad de avanzar en producciones sostenibles.

“Con la expansión de la frontera agrícola, se hace evidente la escasez de materias primas para las artesanías, surge la necesidad de avanzar en una producción sostenible" (Entrevistado 8, 7 de julio de 2011).

El SAC es creado por el Grupo de Mercados Verdes del Ministerio de Ambiente (actualmente en la Dirección de Gestión Ambiental, Crecimiento Verde y Cambio Climático del MADS), en el marco del Plan Estratégico Nacional de Mercados Verdes, con los objetivos de contribuir en la consolidación de bienes ambientales sostenibles, incrementar la oferta de servicios ecológicos competitivos en los mercados nacionales, diferenciar los productos que respetan criterios de sostenibilidad ambiental, generar valor agregado en estos productos y apoyar su posicionamiento en el mercado nacional e internacional. 
En la figura 1, se muestra la evolución del instrumento, cabe resaltar su reglamentación a través de la Resolución 1555 de $2005^{1}$ expedida en conjunto con el Ministerio de Comercio, Industria y Turismo (MCIT), así como las Normas Técnicas Colombianas (NTC) ${ }^{2}$ para las tres categorías de productos elaborados con materias primas vegetales mencionadas anteriormente.

Luego de ocho años del SAC, los entrevistados coinciden en resaltar que la implementación del instrumento en las categorías en mención ha sido nula, resaltando que los únicos avances han sido en el diseño de la norma.

"El sello ha tenido mejores resultados en sectores diferentes al de productos relacionados con la biodiversidad" (Entrevistado 15, 29 de junio de 2011).

Los principales resultados del SAC se han concentrado en categorías diferentes como la de establecimientos de alojamiento y hospedaje, ningún producto en las tres categorías que abordan artesanías con fibras naturales (fique, caña flecha y enea) ha sido certificado. De esta forma, las ventajas que representa el sello para la incursión en nuevos mercados ha sido reconocida por sectores diferentes al artesanal.

La escasa implementación del instrumento, señalan los entrevistados, obedece a una institucionalidad frágil, elevados costos de la certificación y debilidad en el diseño de los instrumentos.

“En el país no existe una institucionalidad que comprenda estas herramientas voluntarias de autogestión, que las promocione y las articule con otros actores nacionales, regionales de los sectores público y privado" (Entrevistado 15, 29 de junio de 2011).

Con respecto a las tarifas no sólo se argumenta que las comunidades artesanales no están en capacidad de asumir los elevados costos directos que implica el proceso de certificación, sino también la falta de gestión de recursos por parte de las diferentes entidades interesadas en promover el

1 Ministerio de Ambiente, Vivienda y Desarrollo Territorial. Resolución 1555 de 2005. Por medio de la cual se reglamenta el uso del Sello Ambiental Colombiano.

2 NTC 5517-2007. Criterios ambientales para embalajes,..., sogas y telas de fibra de fique. NTC 5637-2008. Criterios ambientales para artesanías,.. y otros productos en fibras de fique con tecnología artesanal. NTC 56714-2009. Criterios ambientales para artesanías, sombreros y otros productos en fibras de caña flecha con tecnología artesanal. NTC 5911-2012. Criterios ambientales para artesanías elaboradas en fibras de enea y junco con tecnología artesanal. 
sello, así como la ausencia de claridad en el país de que actualmente variables diferentes al precio jueguen un papel relevante al momento de elegir un bien, reduciendo la posibilidad de incrementar los beneficios una vez productos elaborados con estas fibras vegetales y técnicas artesanales cuenten con el SAC.

Las debilidades en el diseño del instrumento fueron un elemento constante en las entrevistas, por un lado, se resaltó que debido a que la certificación contempla todo el proceso productivo, considerando aspectos ambientales, legales, sociales, etc., el cumplimiento de la norma técnica se complejiza.

“Existe un mito en el pensar que los productos que se sustentan de los recursos
naturales son amigables con el medio ambiente... Y dado que la norma técnica
no puede ser inferior en sus estándares a la normatividad vigente, los artesanos,
un grupo aún generalmente informal en el país, difícilmente pueden cumplir
con al menos lo establecido legalmente" (Entrevistado 5, 12 de julio de 2011).

Por otra parte, también se señaló que el proceso de construcción de la norma no ha sido lo suficientemente participativo, de tal forma que los estándares no integran la realidad de las comunidades donde deberían ser implementados.

\begin{abstract}
“Aunque el proceso de construcción de la norma ha contemplado la participación de los artesanos, hay ausencia de un trabajo previo y posterior al surgimiento de la norma, que permita en primera instancia al artesano comprender e interiorizar el proceso y a su vez aportar más intensamente en su construcción y finalmente lo motive a su posterior aplicación... Los artesanos al momento de conocer la norma se sienten juzgados frente al aprovechamiento que hacen de sus recursos naturales" (Entrevistado 8, 7 de julio de 2011).
\end{abstract}

Finalmente, frente a las tendencias del SAC, las respuestas fueron evasivas con relación a las categorías relacionadas a las fibras vegetales, evidentemente las principales tendencias se orientan a desarrollar el sello para otras categorías. El país de hecho, ha priorizado ciertos productos para su certificación y en el listado no se encuentra ningún producto cuyo insumo principal provenga de la biodiversidad, los principales retos se orientan al sector de la construcción, plomería u electricidad, entre otros. 


\section{Pago por Servicios Ambientales}

El pago por servicios ambientales ha surgido como mecanismo que internaliza las externalidades positivas, permitiendo la financiación de incentivos a actores locales que con sus actividades productivas proveen servicios ambientales a la sociedad (Engel et al., 2008), compensando así directamente al propietario por las pérdidas económicas asociadas a la conservación de los recursos naturales con pagos que corresponden a los servicios mantenidos (Alix - García et al., 2004; Pagiola, 2002).

\section{Pago por servicios ambientales (PSA) experiencia nacional}

Sobre el surgimiento del PSA en Colombia existen acuerdos entre los entrevistados, quienes señalan que debido a las experiencias positivas del instrumento en otros países, principalmente Costa Rica, México y Ecuador, en Colombia se comienza a abordar el instrumento.

"El boom internacional del tema y los crecientes recursos en PSA, hacen que el país también se interese en el instrumento" (Entrevistado 4, 29 de julio de 2011).

Los expertos coinciden en resaltar que el PSA comienza a ser parte de las agendas de trabajo como resultado de las tendencias internacionales que presentan al instrumento como una posibilidad de recursos para invertir en conservación.

“El PSA al igual que REDD es una iniciativa internacional y a nivel de gobierno se adoptan temas de trabajo de acuerdo con las negociaciones internacionales, el PSA es una temática de moda" (Entrevistado 14, 30 de junio de 2011).

“Todos en el país querían un PSA, sin saber que era, ni que implicaciones tenía. De esta forma, el PSA surge más por la demanda existente que por conocer sus bondades y forma de implementación" (Entrevistado 1, 1 de julio de 2012).

El PSA en Colombia, es un instrumento que desde los años ochenta bajo otros nombres ha sido implementado. En la década de los noventa con la iniciativa del Certificado de Incentivo Forestal (CIF) para la conservación, el gobierno colombiano comienza a pensar en pagos por la conservación de servicios ambientales y aunque sus logros son reducidos, el CIF - Conservación corresponde al principal antecedente del PSA en Colombia. Su aparición, está relacionada con la creación en 1990 por 
parte del Ministerio de Agricultura y Desarrollo Rural (MADR) del CIF Reforestación, el cual con base en la experiencia internacional chilena se crea con el objetivo de incentivar la reforestación en el país y reconocer las externalidades positivas generadas por ésta (Colombia 194, Ley 139 de 1994). El CIF - Conservación, es un instrumento económico que reconoce los costos directos e indirectos de la conservación de bosques naturales que asumen los propietarios privados (Colombia, 1997. Decreto 900 de 1997). Sin embargo, el incentivo sólo contó con escasos recursos para su implementación los primeros dos años (IAvH et al. 2000). De acuerdo con Ecoversa (2009) la estimación del costo de oportunidad de conservar fue considerablemente superior al de programas similares existentes en otros países latinoamericanos (\$US 170 ha/año vs \$US 10 - 30 ha/año).

"El incentivo no se implementó debido al elevado valor a pagar estimado" (Entrevistado 12, 6 de julio de 2012).

Esta falta de presupuesto se profundizó a raíz de las reformas institucionales planteadas por el gobierno en el año 2002, al fusionar el Ministerio de Ambiente con el de Desarrollo por medio de la Ley 790 de $2002^{3}$.

Adicional al CIF - Conservación, los entrevistados mencionaron las experiencias descritas en el Cuadro 2 como antecedentes importantes del PSA en Colombia, considerando logros significativos como los primeros instrumentos económicos y financieros desarrollados formalmente en el país para aportar a la conservación de los recursos naturales, así como el programa de investigación en uso y la valoración del Instituto de Investigaciones Biológicas Alexander von Humboldt (IAvH) y las primeras tres experiencias locales en PSA que surgieron en el país y que sustentan gran parte de los recientes ejercicios desarrollados actualmente en Colombia.

Colombia a diferencia de Costa Rica y México ha intentado desarrollar esquemas de PSA locales que permitan acercar a los proveedores de servicios ambientales y los usuarios finales, siguiendo esquemas con compradores o beneficiarios del servicio en su mayoría privados u organizaciones no gubernamentales interesadas en la conservación, con una mínima intervención de las entidades del Estado.

3 Colombia. 2002. Congreso de Colombia. Ley 790 de 2002. Por la cual se expiden disposiciones para adelantar el programa de renovación de la administración pública y se otorgan unas facultades extraordinarias al Presidente de la República. 


\begin{tabular}{|c|c|}
\hline Experiencia & Descripción \\
\hline $\begin{array}{l}\text { Instrumentos económicos y } \\
\text { financieros }\end{array}$ & $\begin{array}{c}\text { Conjunto de instrumentos sustentados legalmente en la Ley } 99 \text { de } 1993 \text { y } \\
\text { reglamentados posteriormente como: } \\
\text { Tasa por uso de agua: Gravamen a la utilización de aguas por personas } \\
\text { naturales o jurídicas, públicas o privadas, destinado al pago de los gastos de } \\
\text { protección y renovación de los recursos hídricos. } \\
\text { Tasa retributivas y compensatorias: Gravamen por las consecuencias nocivas } \\
\text { de la utilización directa o indirecta de la atmósfera, agua y suelo, para } \\
\text { introducir o arrojar desechos o desperdicios de las diferentes actividades } \\
\text { antrópicas, sean o no lucrativas. } \\
\text { Transferencias del sector eléctrico: Las empresas generadoras de energía } \\
\text { hidroeléctrica cuya potencia nominal instalada total supere los } 10.000 \\
\text { kilovatios, transferirán el 6\% de las ventas brutas de energía por generación } \\
\text { propia. } \\
\text { (Adaptado de Ley } 99 \text { de 1993). }\end{array}$ \\
\hline $\begin{array}{c}\text { Programa de uso y valoración } \\
\text { del IAvH }\end{array}$ & $\begin{array}{l}\text { Programa estratégico (1995 - 2008) del Instituto de Investigaciones Bio- } \\
\text { lógicas Alexander von Humboldt que abordaba tres líneas: uso y saberes } \\
\text { locales, valoración y equidad, y biocomercio (Gaitán y García, 2008). } \\
\text { La línea de valoración y equidad trabajó en el año } 2004 \text { trabajó en el diseño } \\
\text { e implementación de instrumentos de política para la conservación y uso } \\
\text { sostenible de la biodiversidad; en el marco de lo cual avanzó con el diseño y } \\
\text { desarrollo del PSA en la microcuenca de Chaina (IAvH, 2005). } \\
\text { En el } 2008 \text { la línea continuó funcionando, hasta que conforme con las } \\
\text { recomendaciones y decisiones de la Junta directiva del Instituto, la Directora } \\
\text { realizó un proceso de reingeniería institucional en el que la línea desapare- } \\
\text { ció (Baptiste et al., 2010). }\end{array}$ \\
\hline $\begin{array}{l}\text { Experiencia local: Asociaciones } \\
\text { de usuarios de agua en el Valle } \\
\text { del Cauca }\end{array}$ & $\begin{array}{l}\text { Múltiples asociaciones de usuarios del agua creadas desde } 1987 \text { con el obje- } \\
\text { tivo de recaudar fondos por medio del cobro de una sobretasa para invertir } \\
\text { en la conservación de las cuencas que abastecen una de la regiones más } \\
\text { fértiles y de mayor productividad en Colombia, el Valle del Cauca. } \\
\text { Aunque con cambios, actualmente está vigente y cuenta con el apoyo de } \\
\text { nuevas organizaciones para su implementación. }\end{array}$ \\
\hline $\begin{array}{l}\text { Experiencia local: Enfoques } \\
\text { silvopastoriles integrados para } \\
\text { el manejo de ecosistemas }\end{array}$ & $\begin{array}{l}\text { Proyecto realizado en el período } 2001 \text { - } 2006 \text { en la cuenca del río La Vieja } \\
\text { (Quindío) en convenio con el Fondo Mundial Ambiental (GEF por sus siglas } \\
\text { en inglés), el Banco Mundial y CIPAV (Centro para la Investigación en Siste- } \\
\text { mas Sostenibles de Producción Agropecuaria). Con el objetivo de mejorar el } \\
\text { funcionamiento ecosistémico de pasturas a través de sistemas silvopastori- } \\
\text { les intensivos que brinden servicios ambientales globales (biodiversidad y } \\
\text { carbono) y beneficios socio-económicos locales (Blanco et al., 2006). } \\
\text { Dados los resultados positivos obtenidos por el proyecto, en el } 2011 \text { inicia } \\
\text { el proyecto nacional de ganadería sostenible con énfasis en biodiversidad, } \\
\text { focalizado en cinco regiones del país. }\end{array}$ \\
\hline $\begin{array}{l}\text { Experiencia local: } \\
\text { Microcuenca del río Chaina }\end{array}$ & $\begin{array}{l}\text { Acuerdo de pago entre los propietarios de los predios de la microcuenca del } \\
\text { río Chaina y los beneficiarios del agua ( } 3 \text { juntas administradoras de agua y } \\
2 \text { acueductos rurales) en relación al control de sedimentos y regulación de } \\
\text { caudal, con los aportes de los usuarios adscritos a las juntas administradoras } \\
\text { o a los acueductos (más de } 5000 \text { personas) (Borda, 2007). } \\
\text { El esquema inicia su implementación en el año } 2005 \text { y los pagos se efectúan } \\
\text { a partir del año } 2007 \text { (Borda et al., 2010). }\end{array}$ \\
\hline
\end{tabular}

Fuente: Elaboración de las autoras.

Frente a los objetivos del instrumento, los entrevistados coinciden en que el principal es la conservación de los recursos naturales, de los bienes y servicios ambientales que proveen. En su conjunto, todos señalan que 
objetivos de pobreza asociados a beneficiar comunidades con bajos ingresos es un elemento adicional que puede o no estar presente.

"El interés en reducir la pobreza a través de estos mecanismos no es explícito"(Entrevistado 19,15 de julio de 2011).

La evolución del PSA en el país, se describe en la figura 2.

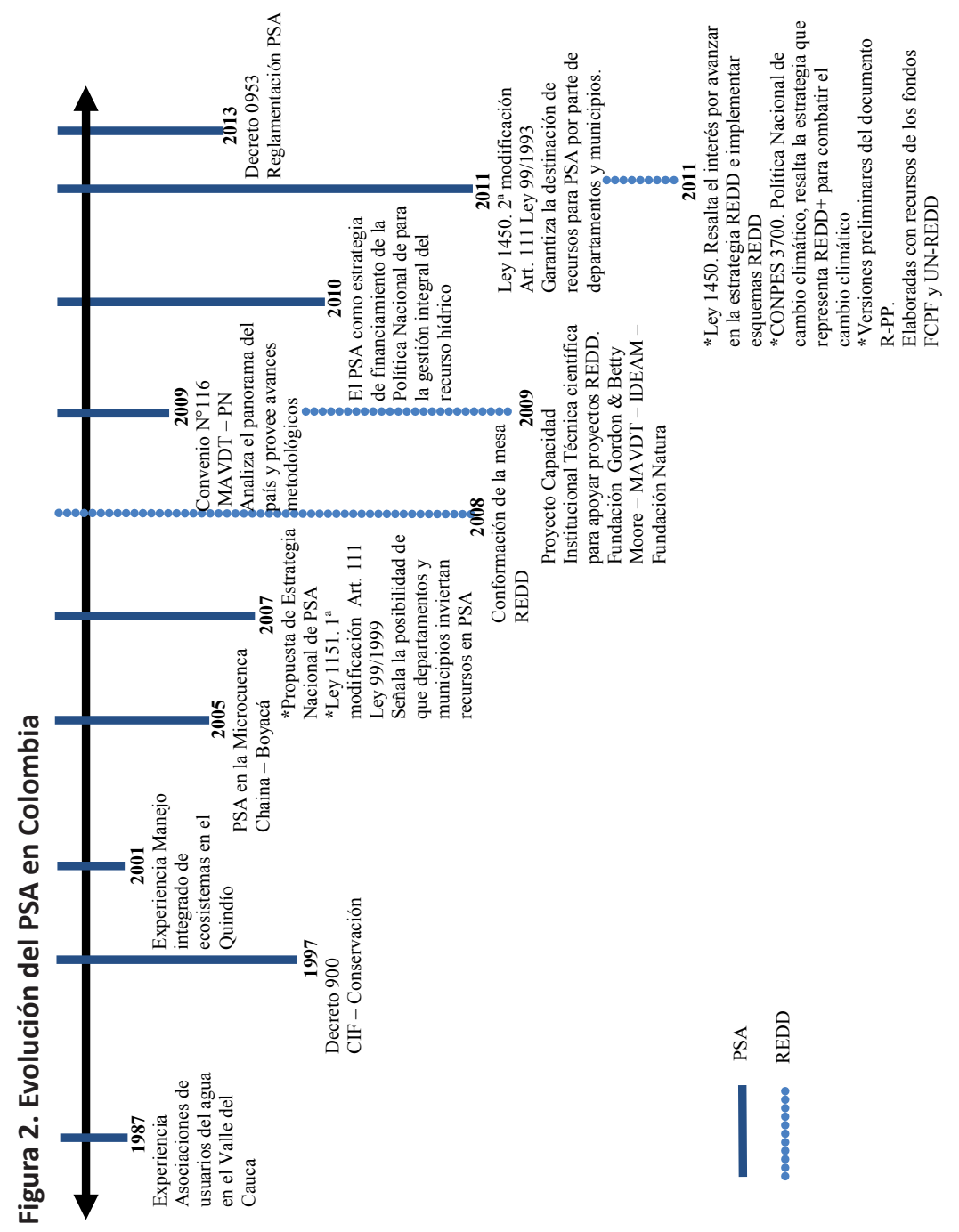


Resaltan la propuesta de Estrategia Nacional (Ecoversa Ecosecurities, 2007), las dos modificaciones del artículo 111 de la ley 99 de 1993 y la reciente reglamentación del artículo en mención, que facilitan y garantizan a futuro la inversión de recursos en esquemas de PSA por parte de departamentos, distritos y municipios.

Con respecto a la implementación, en el marco del convenio $\mathrm{N}^{\circ} 116$, suscrito entre el Ministerio de Ambiente, Vivienda y Desarrollo Territorial (hoy Ministerio de Ambiente y Desarrollo Sostenible) y Patrimonio Natural Fondo para la Biodiversidad y Áreas Protegidas, se realizó un censo que permitió conocer el estado de avance del instrumento (Moreno y Borda, 2009), en el que se encontró que en 2010, en Colombia se estaban proyectando, diseñando e implementando alrededor de 35 experiencias de PSA, con un estado incipiente de avance, pues tan sólo el $8 \%$ estaban en implementación.

"La realidad del país es que se habla mucho de PSA; sin embargo, los avances son pocos" (Entrevistado 9, 27 de julio de 2011).

De acuerdo con los expertos, al analizar los logros en la implementación se deben resaltar tres elementos: conocimiento y conceptualización, financiación voluntaria e institucionalidad.

El conocimiento y la conceptualización, se relacionan con la investigación generada en torno al PSA. Este es considerado por los entrevistados como el principal avance que ha tenido el instrumento en el país.

"Hay un avance significativo, en los últimos cuatro años se ha conocido, conceptualizado y se han realizado aplicaciones concretas del instrumento" (Entrevistado 14, 30 de junio de 2011).

Sin embargo, aunque se resaltan avances, los actores relevantes señalan que aún hay incertidumbres que impiden contar con la capacidad técnica para multiplicar la implementación del PSA, siendo necesario continuar estudiando el instrumento e iniciar procesos de evaluación de los esquemas existentes.

"En el país aún no está muy claro el funcionamiento del esquema" (Entrevistado 19, 15 de julio de 2011).

"Se desconoce cómo vincular el PSA a otras iniciativas, cómo pagar, cuánto pagar, quién lo debe manejar, cuáles son los costos de transacción..." (Entrevistado 14, 30 de junio de 2011). 
Por otra parte, también se resalta que aunque la propuesta durante los últimos años ha sido avanzar en la comprensión del instrumento, esto ha derivado en obstáculos reales para su implementación.

Expertos coinciden en señalar la relevancia de profundizar en la financiación de los esquemas, pues sumado a la escasa intervención del gobierno en la implementación del instrumento, se resalta que de no existir una fuerte escasez del recurso o servicio ambiental y una necesidad explícita por parte de los usuarios del servicio, la financiación por parte de externos es insostenible, de tal forma que el instrumento no responde realmente a la buena voluntad sino al reconocimiento real de los costos de no contar con el servicio o reducir su calidad.

“Financiar el PSA con recursos de los usuarios reales es imposible o inestable, por ser un mecanismo voluntario no existe la conciencia de pago, puede ser que con el tiempo tenga resultados satisfactorios, pero en las condiciones actuales, no lo es... Hay que ser honestos, la buena voluntad no existe, hay un interés por los beneficios que hay detrás del PSA" (Entrevistado 13, 30 de junio de 2011).

"Todo instrumento voluntario corre el riesgo de desaparecer" (Entrevistado 9, 27 de julio de 2011).

“El funcionamiento del PSA con financiación de externos tiene sostenibilidad, siempre y cuando el servicio conservado como lo es el agua sea escaso y requerido por los usuarios; realmente no termina siendo cuestión de buena voluntad" (Entrevistado 4, 29 de julio de 2011).

Adicional a las dificultades identificadas por los entrevistados en torno a la financiación voluntaria de los esquemas de PSA en el país, los expertos resaltan los reducidos avances que se tienen en materia normativa y que han impedido potencializar la implementación del PSA, debido a que no favorecen la inversión financiera por parte de municipios, distritos y departamentos.

"Existen en el país muchos casos formulados, al hacer el análisis de recursos, se identifica la disponibilidad; sin embargo, la ausencia de un marco legal hace imposible la inversión" (Entrevistado 19, 15 de julio de 2011).

De esta forma, las esperanzas han estado puestas desde el 2010 o quizás desde antes, en la reciente aprobación de la propuesta de Decreto reglamentario de los esquemas de PSA, la cual formaliza la inversión de recursos descrita en las modificaciones al artículo 111 de la Ley 99 de 1993, por 
parte de los entes territoriales (municipios, distritos, gobernaciones) en los esquemas de PSA.

La dificultad para aprobar esta reglamentación refleja de acuerdo con los entrevistados una debilidad institucional evidenciada en la reducida voluntad política, ausencia de recursos financieros, lentitud en la consolidación del sustento legal y el escaso desarrollo del instrumento.

“Ha habido un debilitamiento institucional de la oficina de análisis económico y falta de liderazgo a un alto nivel, la discusión de PSA quedó en niveles técnicos y no hubo una instancia política que permitiera el desarrollo de la herramienta" (Entrevistado 2, 11 de julio de 2011).

En cuanto a las tendencias del instrumento, los entrevistados coincidieron en que el PSA seguirá construyéndose para los servicios ambientales asociados al recurso hídrico, debido a la facilidad de asociar un ecosistema y un usuario con capacidad de pago y resaltaron que se espera que con la reciente aprobación del Decreto 0953 de 2013 sea potenciado el instrumento en el país.

“El PSA tiene un cuarto de hora, el mejor servicio para trabajar es el asociado al recurso hídrico, en otros servicios hay desconocimiento, o el mercado es complejo" (Entrevistado 1, 1 de julio de 2011).

\section{Reducción de emisiones por deforestación y degradación (REDD)}

Paralelo a los avances en el diseño de esquemas de PSA y motivado por las negociaciones internacionales al interior de la Convención marco de las Naciones Unidas para el cambio climático (CMNUCC) surge la reducción de emisiones por deforestación y degradación (REDD), un instrumento orientado al pago por el servicio ambiental captura de carbono, con la ventaja de contar con una demanda definida al nacer con el Protocolo de Kioto y con elementos que lo hacen más eficiente en comparación con los esquemas locales de PSA implementados en el país.

"Dentro de la sombrilla que es PSA, REDD es un instrumento para abordar captura de carbono" (Entrevistado 18, 7 de julio de 2012).

“REDD es un PSA más elaborado para servicios globales, pues incluye conceptos como adicionalidad y fugas, elementos que en PSA locales no están del todo considerados" (Entrevistado 2, 11 de julio de 2012). 
La corta evolución que el instrumento ha tenido en el país (ver figura 2.) resalta tres elementos, la existencia de la Mesa REDD como espacio para contribuir al desarrollo de estrategias, políticas, planes y acciones tempranas de REDD (Consejo Nacional de Política Económica y Social, 2011).

La Ley 1450 de $2011^{4}$ en la que se señala el compromiso de avanzar con la elaboración de la estrategia REDD. Y la Estrategia Nacional para la Reducción de las Emisiones debidas a la Deforestación y la Degradación Forestal y la Función de la Conservación, la Gestión Sostenible de los Bosques y el Aumento de las Reservas Forestales de Carbono en los Países en Desarrollo (ENREDD+), meta del actual gobierno y desarrollada en el CONPES 3700 (FCPF, UN-REDD, 2011).

En cuanto a la implementación, los entrevistados hacen referencia a un proceso de comprensión del instrumento lento e incierto, en concordancia con Ortega et al. (2010) quienes resaltan que aunque existen grandes incertidumbres sobre los lineamientos que se desaten de las negociaciones, el país debe avanzar en la construcción de un marco genérico para avanzar en REDD.

\begin{abstract}
“La lógica de Colombia avanza en la medida en que el tema se mueve a nivel internacional; sin embargo, cada país debe tener su propia lógica de movimiento a nivel interno. Colombia ha tomado la decisión de esperar y no avanzar hasta tanto no se apruebe REDD, pero con o sin REDD hay que controlar la deforestación" (Entrevistado 3, 21 de julio de 2011).
\end{abstract}

Finalmente, los expertos resaltan la debilidad institucional existente en el país para abordar el instrumento, evidente en dos elementos: la dificultad de transversalizar el tema, siendo REDD abordado aisladamente por el Ministerio de Ambiente, debido a que el cambio climático ha sido entendido como competencia del sector ambiental y no como reto que incide en el desarrollo económico y social de la nación (Consejo Nacional de Política Económica y Social, 2011).

Y el reducido desarrollo normativo junto a los escasos lineamientos de política claros para avanzar en la construcción de REDD, conducen a que actualmente en Colombia se adelanten diversas acciones que algunos consideran no están bien articuladas.

4 Ley por medio de la cual se aprueba el Plan Nacional de Desarrollo 2010 - 2014 
“No hay reglas claras para desarrollar instrumentos en Colombia... La visión de las locomotoras no ha dejado ver realmente lo que quiere el gobierno en los bosques" (Entrevistado 10, 5 de septiembre de 2011).

\section{Discusión}

De acuerdo con IAvH et al. (2000), a finales de la década de los noventa e inicios del año 2000 en Colombia eran pocos los instrumentos o incentivos dirigidos a la conservación y uso sostenible de la biodiversidad. Cerca de diez años más adelante, Ecoversa (2009), resalta que Colombia cuenta con una gran variedad de instrumentos económicos, financieros y tributarios en materia ambiental (contaminación, uso de recursos naturales y residuos sólidos), identificando 28 instrumentos: 10 económicos $^{5}, 9$ financieros $^{6}$ y 9 tributarios $^{7}$.

De los 28 instrumentos identificados por Ecoversa, únicamente cuatro, que a su vez son de implementación voluntaria: tres económicos (Eco-etiquetado, CIF - Conservación y PSA) y uno tributario (Exención de impuesto predial por conservación) se relacionan directamente con la preservación y conservación de los ecosistemas.

$\mathrm{Al}$ igual que en los resultados obtenidos por IAvH et al. en el $2000 \mathrm{y}$ en el 2009 por Ecoversa, los instrumentos económicos para abordar la conservación de los recursos naturales continúan siendo escasos, siguiendo así en Colombia la tendencia de promover el diseño de instrumentos que fomentan el pago por la contaminación y daños causados al ambiente.

Así, los instrumentos económicos voluntarios analizados en el presente trabajo, contemplan la totalidad de instrumentos económicos diseñados

5 Tasa retributiva por vertimientos puntuales, Tasa por utilización de agua, Tasas compensatorias, Tasas de aprovechamiento forestal, Eco-etiquetado, Mecanismo de desarrollo limpio, Certificado de incentivo forestal reforestación, Certificado de incentivo forestal conservación, Pago por servicios ambientales y Compensación municipal al alojamiento de rellenos sanitarios.

6 Inversión forzosa del 1\% de proyectos que utilizan agua sujetos a licencias y distritos de riego, Compensaciones en licencias ambientales, Destinación del 1\% de los ingresos corrientes de los municipios y departamentos, Sobretasa del impuesto predial, Transferencias del sector eléctrico, Tarifas de ecoturismo en Parques Nacionales Naturales, Cobro por servicios de evaluación y seguimiento, Regalías nacionales con destinación ambiental y Compensaciones de explotación de minerales.

7 Deducciones de IVA en tres tipos de productos, Deducciones de renta descrita en 5 artículos de la Reforma tributaria y Exención de impuesto predial por conservación. 
en Colombia para abordar directamente la conservación de los recursos naturales del país.

En el cuadro 3, se comparan los resultados obtenidos en el surgimiento, evolución y tendencias de los instrumentos objeto de estudio y se resaltan variables relevantes de las entrevistas realizadas.
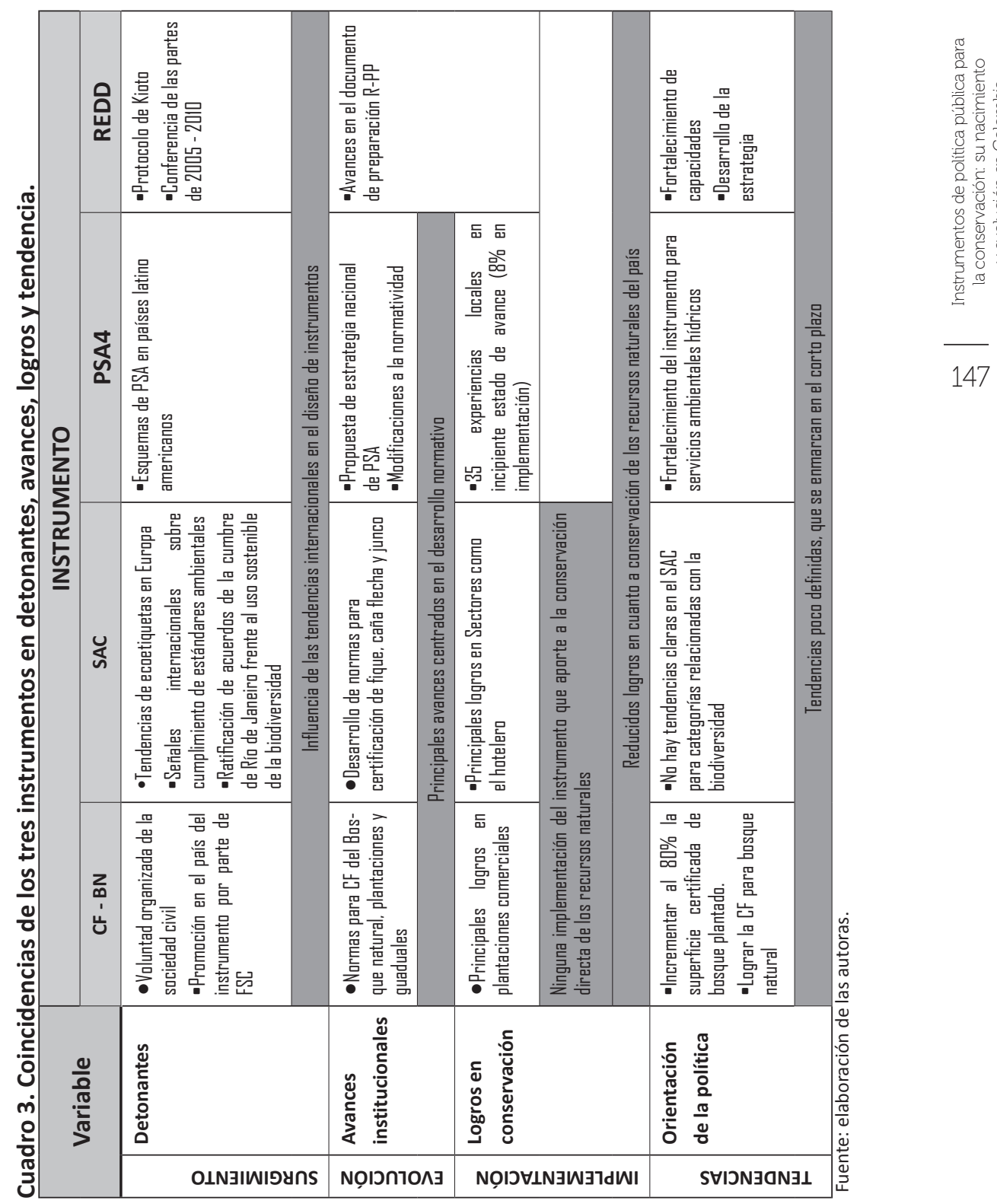
Aunque no se evidencia relación causal directa entre los instrumentos económicos voluntarios analizados, la variable detonante permite identificar la influencia de las tendencias internacionales en el surgimiento de los instrumentos económicos voluntarios para la conservación.

"La importancia de las tendencias internacionales es una constante en el campo ambiental del país, donde la disponibilidad de recursos internacionales define las líneas temáticas a abordar, las cuales son abandonadas una vez la inversión se reduce" (Entrevistado 17, 8 de julio de 2011).

Siendo la Declaración de Río en 1992, el evento más relevante en la promoción del diseño e implementación de estos instrumentos, pues es el origen de la Agenda 21 que abre el espacio para avanzar en certificación forestal, sienta las bases del Convenio sobre diversidad biológica que enfatiza en el uso sostenible de la biodiversidad y el desarrollo de incentivos para la conservación y abre el camino a la Convención marco de las Naciones Unidas sobre cambio climático que a partir de 2005 favorece el ambiente para iniciar a desarrollar REDD.

Los avances en el etiquetado europeo (1992), la consolidación del FSC (1994), los resultados de los esquemas de PSA en Costa Rica (1997) y México (2003) se encuentran entre los principales detonantes para que Colombia incursione en el diseño de estos instrumentos.

Lo anterior, en concordancia con Rodríguez-B y Espinoza (2002) quienes señalan que las agencias internacionales y la banca multilateral han tenido un impacto significativo en las instituciones, políticas e instrumentos ambientales en América Latina y el Caribe.

Por otra parte, la variable avances institucionales permite señalar que en la evolución de los instrumentos en el país, las principales etapas se han centrado en el desarrollo de normas que detallan el diseño de los instrumentos o buscan reglamentarlo. Asimismo, se observa que tanto en certificación como en PSA las primeras experiencias o antecedentes son importantes para el avance de los instrumentos. Sin embargo, la variable logros en conservación refleja la nula o reducida implementación que los instrumentos han tenido.

Por último la variable orientación de política evidencia que en el país, ninguno de los cuatro instrumentos económicos voluntarios cuenta con tendencias definidas. El SAC no tiene en el largo plazo metas concretas en cuanto a productos de la biodiversidad se refiere, la CF pretende incrementar la superficie certificada de bosque plantado y el PSA debate en un panorama incierto la definición de pasos a seguir finalmente, en cuanto a 
REDD, aún en una fase temprana de construcción, no cuenta con tendencias claras.

En la figura 3, se compara la evolución de los instrumentos, se resaltan los principales avances de cada uno de ellos y por medio de barras en la parte inferior se representan los períodos de tiempo con mayor o menor número de logros.

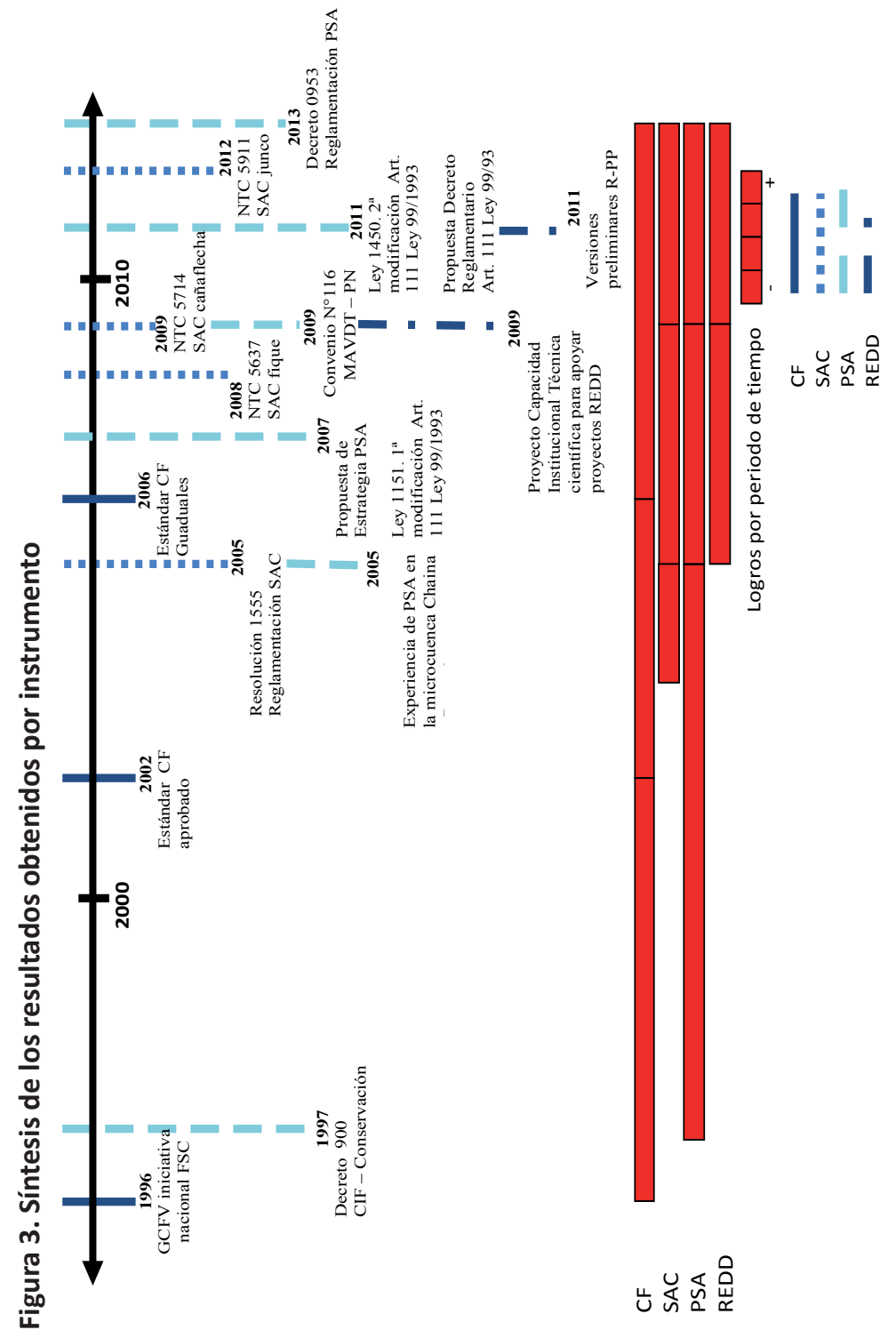


Los difusos resultados, reflejan las tendencias por abordar en el país instrumentos por cortos períodos de tiempo que no logran superar la fase de novedad por la que son promovidos.

“Las modas definen los períodos en los que se trabajan más fuertemente estos incentivos, con el pasar del tiempo así sean importantes pasan a un segundo plano, actualmente la mirada se ha volcado a nuevos instrumentos como tasas compensatorias por aprovechamiento forestal y REDD" (Entrevistado 11, 29 de junio de 2011).

De esta manera se evidencia que en Colombia los instrumentos para la conservación rápidamente pierden vigencia y aunque el diseño e implementación de un instrumento no ha concluido, los esfuerzos institucionales se comienzan a orientar al diseño de nuevas herramientas. Actualmente ninguno de los instrumentos analizados es parte fundamental de la política pública que en materia de conservación se desarrolla en el país.

El país no tiene una mirada clara a la importancia de estos instrumentos, Colombia reacciona de acuerdo con las necesidades que se van presentando, si la urgencia es la ola invernal, los recursos que estaban destinados a conservación, se van ahora a concentrar en infraestructura" (Entrevistado 1, 1 de julio de 2011).

Lo anterior ha sido señalado por Redford y Adams (2009) quienes indican que las políticas de conservación ponen mucha fe en nuevos instrumentos pero que después de algunos años no cumplen con las expectativas generadas. Los resultados hacen evidente esta afirmación en ell cso de los dos instrumentos estudiados.

Los actores relevantes entrevistados argumentan que esto se debe a elementos como la ausencia de voluntad política, expresada en la debilidad jurídica y normativa para promover los instrumentos y los reducidos recursos financieros que han limitado la implementación. Estos señalamientos reafirman lo indicado por Valencia (2010) quien resalta que la política de conservación ambiental más que un problema de leyes y regulación es un problema de intereses y voluntad política.

Rudas (2008) indica que la pérdida de prioridad de la política ambiental para el gobierno colombiano se visibiliza en el constante debilitamiento presupuestal del ministerio de ambiente.

En el caso de PSA las dificultades institucionales para consolidar ésta política han sido señaladas en otros países como Indonesia o Camerún (Pirard, 2012; Somorin et al., 2013). Algunos de los aspectos que se han señalado 
son la dificultad de descentralizar y disminuir los costos administrativos, lo cual en el caso de Colombia limita las posibilidades de ampliar la cobertura del instrumento. Asimismo, la imposibilidad de algunos usuarios de solventar el pago de un servicio ambiental, como lo indica Pirard (2012), explica porque en Colombia el instrumento se ha localizado en zonas más urbanas en donde hay instituciones pre-establecidas y usuarios que pueden pagar el costo de la conservación pero evidentemente esto no da prioridad a las áreas más biodiversas y de mayor pobreza.

Las políticas ambientales corresponden a realidades complejas en donde se entrelazan diferentes problemas del desarrollo, por lo que requieren de políticas más integrales (Mermet et al., 2012). El presupuesto y diseño de la política difícilmente será integral desde una planeación sectorial y esto dificulta a su vez la implementación de instrumentos ambientales. El arreglo institucional inadecuado, la falta de participación de la sociedad y la dificultad de definir los actores son los principales factores que muestran la debilidad institucional a la que se enfrentan muchos países (Pirard, 2012).

Al detallar los Planes Nacionales de Desarrollo de los diferentes gobiernos de Colombia a lo largo de la línea de tiempo considerada para estos tres instrumentos, se observa un mayor interés en el sector ambiental entre 1990 y 1998, período en el que se crea el Ministerio de Ambiente, se expide la Ley 99 del 1993 y se elaboran la Política de Bosques (CONPES 2834 de 1996) y la Política Nacional de Biodiversidad (1996, actualmente en ajustes), posteriormente, poco a poco los objetivos ambientales se fueron diluyendo hasta en el 2002 fusionar el Ministerio de Ambiente con Vivienda y Desarrollo Territorial, dando un giro a la política ambiental, evidente en los escasos resultados que difícilmente han superado el diseño de normas para su implementación.

"La debilidad de los instrumentos actualmente se relaciona directamente con la debilidad institucional. Existe debilidad en la planeación e implementación, Colombia es muy exitoso en el desarrollo de política ambiental, política simbólica, pues difícilmente se concretan las cosas. Evidentemente existe una falta de voluntad política debido a la baja prioridad que representa el sector ambiental en el país" (Entrevistado 17, 8 de julio de 2011).

Frente a esto, en el informe de la CGN (2010) se resalta que la política ambiental cuenta con una institucionalidad débil, como consecuencia de los cambios institucionales dados en el período de gobierno 2002-2006 que debilitaron la capacidad de gestión y afectaron considerablemen- 
te la institucionalidad construida en el sector ambiental (Valencia, 2010; Rodríguez-B., 2007).

Que el país continúe ignorando su responsabilidad con los recursos naturales, además de reflejar la escasa importancia que el Estado ha otorgado a la protección de los ecosistemas (Ramírez et al., 2000), resalta la debilidad institucional del sector ambiental no sólo a niveles de tomadores de decisiones de elevada jerarquía.

"La conservación de las zonas boscosas del país no debe hacerse a partir de proyectos, debe ser una política de estado..., la conservación no debe ser vista solamente en el corto plazo" (Entrevistado 10, 5 de septiembre de 2012).

En concordancia con Rodríguez-B (1993) quien señala que la conservación de los recursos naturales en el país le interesa a un pequeño porcentaje de la población y a un reducido grupo de las clases dirigentes del sector público y privado a nivel nacional, regional y local.

De esta forma, Valencia (2010) y Rodríguez-B. y Espinoza (2002) resaltan la necesidad de avanzar en el fortalecimiento del tejido institucional y en la creación de capacidades en la búsqueda de una mayor participación proactiva.

La debilidad institucional del sector ambiental en el país, refleja también la ausencia de reconocimiento de las normas, creencias y valores existentes en las comunidades que hacen uso de los recursos naturales y resalta los reducidos esfuerzos por fortalecer la conformación de redes que promuevan y detonen iniciativas de conservación. Es notorio en el caso de Colombia que la política ambiental ha sido simplista y no una política compleja que se caracteriza por una mayor colaboración entre los distintos actores incluyendo a las comunidades (Regeer, 2009).

Esta debilidad hace evidente que los procesos de conservación en el país continúen siendo estrictamente verticales, ignorando el verdadero rol que desempeñan organizaciones no gubernamentales y actores locales en el diseño, adaptación e implementación exitosa de estos instrumentos, permaneciendo ausente el diseño de políticas horizontales que aborden no sólo desde el sector ambiental la problemática que afrontan los recursos naturales, sustento de la economía de múltiples comunidades y generadores de bienestar para los habitantes de la nación. 


\section{Bibliografía}

Aguilar, L., 2009, "Marco para el análisis de las políticas públicas”, en Freddy Mariñez Navarro, y Vidal Garza Cantú, (coords.), Política pública y democracia en América Latina. Del Análisis a la implementación, México, Miguel Angel Porrúa, pp.11-31.

Alix-García, J., de Janvry, A., y Sadoulet, E. 2004, Payments for environmental services: to whom, where, and how much? Paper presented at Workshop on Payment for Environmental Services. Guadalajara, México: INE/CONAFOR/World Bank.

Babbie, E. 1988, Métodos de investigación por encuesta, Traducción de Juan José Utrilla. México, Fondo de Cultura Económica.

Banco Mundial, 1997, "Five years after Rio: Innovations in environmental policy", Environmentally Sustainable Development Studies and Monograph Series $N^{\circ} 18$.

Baptiste, B., L. Mosquera, y C. Villa (comp.), 2010, Informe anual 2009, Instituto de Investigaciones Biológicas Alexander von Humboldt, Colombia, IAvH.

Barde, J., 1995, “Environmental policy and policy instruments”, en H. Folmer, L. Gabel, y H. Opschoor, (eds.), Principles of environmental and resource economics. A guide for students and decision makers, United Kingdom: Biddles Ltd, Guildford and King's Lynn.

Baumol, W.J. y W.E. Oates, 1988, The Theory of Environmental Policy, Cambridge, Cambridge University Press.

Blanco, J., S. Wunder, y F. Navarrete, 2006, La experiencia colombiana en esquemas de pago por servicios ambientales. Ecoversa - Cifor. Último acceso septiembre de 2011, www.cifor.org/pes/publications/pdf_files/colombia_experience.pdf.

Borda, C, 2007, Experiencia en la implementación de una esquema de pagos por servicios ambientales en la microcuenca de Chaina, Departamento de Boyacá, Colombia, Informe Final. Documento interno de trabajo, Colombia, Instituto de Investigación en Recursos Biológicos Alexander von Humboldt.

Borda, C., R. Moreno-Sánchez, y S. Wunder, 2010, Pagos por servicios ambientales en marcha: La experiencia en la Microcuenca de Chaina, Departamento de Boyacá, Colombia, Colombia, Centro para la Investigación Forestal Internacional. 
Cabrera, E., D. Vargas, G., Galindo, M. García, y M. Ordoñez, 2011, Memoria técnica de la cuantificación de la deforestación histórica nacional. Escalas gruesa y fina, Bogotá, Instituto de Hidrología, Metereología y Estudios Ambientales IDEAM.

CEPAL, PNUMA, SEMARNAP, 1998, Instrumentos económicos para la gestión ambiental en América Latina y el Caribe, México, SEMARNAP.

CGN, 2010, Informe el estado de los recursos naturales y el ambiente 2009 - 2010, Bogotá, Contraloría General de la Nación.

Chowdhury, M., y M. Koike, 2010, “An overview on the protected area system for forest conservation in Bangladesh", Journal of Forestry Research, vol. 21, pp.111118.

Colombia, 1997, Ministerio del Medio Ambiente. Decreto 900 de 1997. Por medio del cual se reglamenta el Certificado de Incentivo Forestal para la Conservación.

Colombia, 1994, Congreso de Colombia. Ley 139 de 1994. Por medio del cual se crea el Certificado de Incentivo Forestal y se dictan otras disposiciones.

Colombia, 1993, Congreso de Colombia. Ley 99 de 1993. Por medio de la cual se crea el Ministerio del Medio Ambiente, se reordena el Sector Público encargado de la gestión y conservación del medio ambiente y los recursos naturales renovables, se organiza el Sistema Nacional Ambiental - SINA y se dictan otras disposiciones.

Consejo Nacional de Política Económica y Social, 2011, CONPES 3700. Estrategia Institucional para la articulación de políticas y acciones en materia de cambio climático en Colombia.

Coomes, O., F. Grimard, C. Potvin, y P. Sima, 2008, “The fate of the tropical forest: carbon or cattle?", Ecological Economics, vol. 65, pp. 207 - 212.

Dietz, F. y Vollebergh, H., 2002, “Explaining instrument choice in environmental policies", en J. Van den Bergh, (ed.), Handbook of environmental and resource economics, United Kingdom: Edward Elgar Publishing.

Ecoversa - Ecosecurities, 2007, Estrategia Nacional de PSA - Colombia. Documento Interno de trabajo, Colombia, MAVDT.

Ecoversa, 2009, Recopilación, evaluación y análisis de los instrumentos económicos y tributarios existentes en materia ambiental. Informe final, Colombia, ANDESCO. 
Engel, S., S. Pagiola, y S. Wunder, 2008, “Designing payments for environmental services in theory and practice: An overview of the issues", Ecological Economics, vol. 65, pp. 663-674.

FCPF, UN-REDD, 2011, Propuesta de Preparación para REDD+ (R-PP) Colombia. Versión 5. Último acceso septiembre de 2011. www.minambiente.gov.co/documentos/DocumentosAmbiente/cambio_climatico/280911_r_pp_colombia_ ver_05.pdf.

Gaitán, M., y O. García (comps.), 2008, Informe anual 2007 Instituto de Investigaciones Biológicas Alexander von Humboldt, Colombia, IAvH.

Garza, A. 1970. Manual de técnicas de investigación para estudiantes de ciencias sociales. México: El Colegio de México.

GTZ, FSC, GTCFV, 2004, Certificación forestal voluntaria una herramienta para ingresar a nuevos mercados, Colombia, GTCFV.

Hanley, N., J. Shogren, y B. White, 2007, Environmental economics in theory and practice, New York: Palagrave Macmillan.

Ho, L, 1994, Programa de Cooperación del Programa de Naciones Unidas para el Desarrollo PNUD a la gestión ambiental en Colombia, Colombia, Departamento Nacional de Planeación.

Horan, R.y J. Shortle, 2001, “Environmental instruments for agriculture”, en J. Shortle, y D. Abler, D. (eds.), Environmental policies for agricultural pollution control. USA: Department of agricultural economics and rural sociology, Pennsylvania State University.

Howlett, M, 2007, “What is a policy instrument? Policy tools, policy mixes and policy implementation styles", en E. Pearl, M. Hill y M. Howlett (eds.), Designing government. From instruments to governance, Canada, McGill-Queen's University Press.

IAvH, 2005, Informe anual 2004 Instituto de Investigación de Recursos Biológicos Alexander von Humboldt, Colombia, IAvH.

IAvH, DNP, WWF, RRSC, UAESPNN, 2000, Incentivos para la conservación y uso sostenible de la biodiversidad, Bogotá, Instituto de Investigación de Recursos Biológicos Alexander von Humboldt. 
IDEAM, 2010, Informe anual sobre el estado del medio ambiente y los recursos naturales renovables en Colombia. Bosques 2009, Bogotá, Instituto de Hidrología, Meteorología y Estudios Ambientales.

IUCN, 1980, World conservation strategy. Living resource conservation for sustainable development, IUCN, UNEP, WWF. Último acceso octubre de 2012. www.data. iucn.org/dbtw-wpd/edocs/WCS-004.pdf.

Jones, N., C. Gleridou, P. Dimitrakopoulos, y K, Evangelinos, 2012, “Investigating social acceptability for public forest management policies as a function of social factors", Forest Policy and Economics, vol. 14, pp. 148 - 155.

Khanna, M., 2001, “Non-mandatory approaches to environment protection”, Journal of Economics Surveys vol. 15, pp. 291-324.

Laurance W., 2007, “A new initiative to use carbon trading for tropical forest conservation", Biotropica, vol. 39, pp. 20-24.

Matose, F., 2006, "Co-management options for reserved forests in Zimbabwe and beyond: policy implications of forest management strategies", Forest Policy and Economics, vol. 8, pp. $363-374$.

MAVDT, ICONTEC, 2006, Selección y normalización de categorías de producto para el Sello Ambiental Colombiano, Colombia, Ministerio de Ambiente, Vivienda y Desarrollo Territorial, Instituto Colombiano de Normas Técnicas y Certificación.

Mermet, L., R. Billé, y M. Leroy, 2010, “Concern-Focused Evaluation for Ambiguous and Conflicting Policies: An Approach From the Environmental Field" American Journal of Evaluation, vol. 31, pp: 180-198.

Ministerio de Ambiente, 2002, Programa Nacional. Lineamientos de etiquetado ambiental para Colombia. Documento interno de trabajo, Colombia.

Misra, D., y S. Kant, 2004, "Production analysis of collaborative forest management using an example of joint forest management from Gujarat, India", Forest Policy and Economics, vol. 6, pp. $301-320$.

Moreno, C., y C. Borda, 2009, Definición del mecanismo de evaluación y selección de las iniciativas y proyectos de PSA actualmente en diseño, formulación y/o implementación a nivel nacional. Informe final en el marco del Convenio $\mathrm{N}^{\mathrm{o}} 116$ de 2008 suscrito entre el MAVDT y Patrimonio Natural Fondo para la Biodiversidad y las Áreas protegidas. Colombia. 
Muradian, R., E. Corbera, U. Pascual, N. Kosoy, y P. May, 2010, “Reconciling theory and practice: an alternative conceptual framework for understanding payments for environmental services", Ecological Economics, vol. 65, pp. 712 - 724.

Ortega-P., S., A. García-Guerrero, C-A., Ruiz, J. Sabogal, y D. Vargas (eds.), 2010, Deforestación evitada. Una guía REDD + Colombia, Colombia, Ministerio de Ambiente, Vivienda y Desarrollo Territorial, Conservación Internacional Colombia, Fondo Mundial para la Naturaleza (WWF), The Nature Conservancy, Corporación Ecoversa, Fundación Natura, Agencia de Cooperación Americana (USAID), Patrimonio Natural - Fondo para la Biodiversidad y Áreas Protegidas y Fondo para la Acción Ambiental.

Pagiola, S., 2002, "Paying for water services in Central America", en S. Pagiola, J. Bishop, y N. Landell-Mills, (eds.), Selling forest environmental services market-based mechanisms for conservation and development, London, Earthscan Publications.

Parkhurst, G., J. Shogren, C. Bastian, P. Kivi, J. Donner, y R. Smith, 2002, “ Agglomeration bonus: An incentive mechanism to reunite fragmented habitat for biodiversity conservation", Ecological Economics, vol. 41, pp. 305-328.

Parsons, W., 2007, Políticas públicas. Una introducción a la teoría y la práctica de políticas públicas, México, FLACSO.

Pérez, R.; S. Ávila, y A. Aguilar, 2010, Introducción a las economías de la naturaleza, México, UNAM, Instituto de investigaciones económicas.

Pirard, R., 2012, "Payments for Environmental Services (PES) in the public policy landscape: Mandatory species in the Indonesian recipe", Forest Policy and Economics, Vol.18, pp: 23-29.

Ramírez, S., N. Ortíz, y H. Rojas, 2000, Identificación y evaluación de alternativas para la adopción e implementación de un mecanismo de certificación forestal voluntaria en Colombia y metodologías para su aplicación. Informe Final, Colombia, Ministerio del Medio Ambiente.

Rayner J. y M. Howlett, 2009, “Conclusion: Governance arrangements and policy capacity for policy integration", Policy and Society, vol. 28 pp: 165-172.

Redford, K. H. y W.M. Adams, 2009, “Payment for Ecosystem Services and the challenge of saving nature", Conservation Biology, vol. 23, pp. 785-787.

Regeer, B. J., 2009, “Six Guiding Principles for Evaluating Mode-2 Strategies for Sustainable Development”, American Journal of Evaluation, vol. 30, pp: 515-537. 
Rodríguez-B, M. y G. Espinoza, 2002, “Las políticas ambientales”, en D. Wilk, (ed.), Gestión ambiental en América Latina y el Caribe: Evolución, tendencias y principales prácticas, Washington, Banco Interamericano de Desarrollo, Departamento de Desarrollo Sostenible División de Medio Ambiente.

Rodríguez-B., M., 1993. “ ¿A quien le importa la biodiversidad en Colombia? En busca de elementos para su conservación y uso sostenible", en S. Cárdenas y H. Correa (eds.), Nuestra diversidad biológica, Bogotá, Fundación Alejandro Ángel Escobar, CEREC.

Rodríguez-B., M., 2007, “Hacia la insostenibilidad ambiental” en E. Robayo, (coord.), "Hacia la insostenibilidad ambiental. Un balance de la política ambiental 2002 - 2006”, Bogotá, Universidad de los Andes.

Rudas, G., 2008, Indicadores fiscales y económicos de la política ambiental en Colombia, Documento de políticas públicas 26, Bogotá, Foro Nacional Ambiental.

Russel, C.y P. Powell, 2002, "Practical considerations and comparisons of instruments of environmental policy", en J. Van den Bergh, (ed.), Handbook of environmental and resource economics, United Kingdom, Edward Elgar Publishing.

Sterner, T., 2008, Instrumentos de política económica para el manejo del ambiente y los recursos naturales, Turrialba, CATIE.

Somorin, O. A., I. J. Visseren-Hamakers, B. Arts, D.J. Sonwa y A.M. Tiani, 2013, "REDD+ policy in Cameroon: actors, institutions and governance", Environmental Science and Policy, vol 35,_pp. 87-97.

Valencia, L., 2010, “Análisis de la política de conservación ambiental colombiana. Antecedentes, realidades y perspectivas", Ponencia para el segundo Congreso Nacional de Ciencia Política, Barranquilla, Universidad del Norte.

Wunder, S., 2005, "Payments for environmental services: some nuts and bolts", CIFOR occasional paper, núm. 42. Último acceso julio de 2011. www.cifor.org/publications/pdf_files/OccPapers/OP-42.pdf.

Recibido 10 de abril de 2013 Aceptado 22 de octubre de 2013 